\title{
Psychometric properties of the adapted Malay Eating Disorder Examination-Questionnaire 6.0 (EDE-Q 6.0) among university students in Malaysia
}

\author{
Nasehah Mohd Taib $^{\text {a }}$, Jamilah Hanum Abdul Khaiyom ${ }^{\text {,**, Jusmawati Fauzaman }}{ }^{\text {b }}$ \\ ${ }^{a}$ Faculty of Business, Communication and Law, INTI International University, Persiaran Perdana BBN, Putra Nilai, 71800 Nilai, Negeri Sembilan, Malaysia \\ ${ }^{\mathrm{b}}$ Department of Psychology, International Islamic University Malaysia, Jalan Gombak, 53100 Kuala Lumpur, Malaysia
}

\section{A R T I C L E I N F O}

\section{Keywords:}

Eating disorder

Reliability

Validity

Malay

University students

\begin{abstract}
A B S T R A C T
The "Eating Disorder Examination-Questionnaire" (EDE-Q) is a cost-effective eating disorder (ED) screening tool that has a significant relationship with the gold standard "Eating Disorder Examination" (EDE) interview. Though it has been widely used for clinical and research purposes, there is a dearth of effort to establish psychometric properties of the latest EDE-Q 6.0 in the Malaysian sample. The extant study adapted and validated EDE-Q 6.0 on Malaysian university's student population $(N=595)$ from a public university in the Klang Valley, Malaysia. Four factors of Restraint, Shape and Weight Concerns, Eating Concerns, and Shape/Weight Overvaluation were constituted from exploratory factor analysis. Still, they failed to indicate apparent replication of the original English EDE-Q 6.0. Malay EDE-Q 6.0 exhibited high internal consistency reliability $(\alpha=0.93)$, acceptable test-retest reliability over 14 days, and acceptable equivalence reliability of its items with the original English version items. The Malay EDE-Q 6.0 global and subscales scores attained acceptable validity with the global scores of Malay EAT-26 (another ED scale) as evidence of convergent validity and with quality of life (QoL) scale for divergent validity. Accordingly, the adapted EDE-Q 6.0 Malay version is considered a valid and reliable instrument for assessing eating disorder psychopathology among Malaysian university students.
\end{abstract}

\section{Introduction}

Before the 1990s, eating disorders (ED), specifically anorexia nervosa cases, were reported in Malaysia (Buhrich, 1981) and anticipated to increase because of globalization and westernization (Pike \& Dunne, 2015). Unfortunately, Malaysia lacks recent epidemiological data owing to the paucity of ED experts and psychometrically sound screening and diagnostic tools. The Eating Disorder Examination-Questionnaire (EDEQ) (Fairburn \& Beglin, 1994) is a self-reporting indicator of the Eating Disorder Examination interview, which is considered as a 'gold standard' assessment. Moreover, EDE-Q is practical and inexpensive, exhibiting a significant correlation with the Eating Disorder Examination interview, as reported in several comparative studies (Fairburn \& Beglin, 1994). Though widely used for research and clinical purposes, scant research has addressed the latest EDE-Q 6.0 psychometric aspects (Fairburn \& Beglin, 2008) in the Malaysian population sample. Therefore, this study aims to adapt EDE-Q 6.0 for Malaysian use.

In general, the use of EDE-Q 6.0 in the United Kingdom (UK) (Barnes et al., 2012; White et al., 2014), the United States (US) (Darcy et al., 2013; Rand-Giovannetti et al., 2017; Rose et al., 2013), and Australia (AU) (Parker et al., 2015) successfully produced indicators of good reliability and validity. Several adapted EDE-Q 6.0 (Japanese, Italian, French, and Norwegian) also reported internal reliability that ranged between 0.70 and 0.96 (Mohd Taib \& Abdul Khaiyom, 2019, 2020). The Italian EDE-Q 6.0 recorded good test-retest reliability indicators for its global ( $r=0.80)$ and subscale scores $(r=0.66-0.83)$, at a mean interval of 10.1 days (Calugi et al., 2017). The Japanese EDE-Q 6.0 (Mitsui et al., 2017) with a restructured subscale recorded moderate validity with measures of a similar construct, which are Eating Attitude Test-26 (EAT26; Garner et al., 1982) and Eating Disorder Inventory-II (EDI-II; Garner, 1991).

However, the structure of the underlying factor of EDE-Q 6.0 in these studies is highly controversial, when its limited fit is compared to the original four-factor model (Mohd Taib \& Abdul Khaiyom, 2019). A factor analysis review of EDE-Q 6.0 by Rand-Giovannetti et al. (2017) highlighted that most research failed in replicating the original four-

\footnotetext{
* Corresponding author at: Department of Psychology, International Islamic University Malaysia, Jalan Gombak, 53100 Kuala Lumpur, Malaysia.

E-mail address: hanum@iium.edu.my (J.H. Abdul Khaiyom).
} 
factor structure. The failure is evident when alternative factor structures were suggested, namely the three-factor model with all subscale items proposed by Hilbert et al. (2012), White's three-factor model (White et al., 2014), and Friborg's four-factor model (Friborg et al., 2013). In addition, Ramli et al. (2008) performed an exploratory factor analysis (EFA) on 36 items in the earlier adapted Malay EDE-Q among school students in Malaysia. The results suggest a four-factor structure, namely Weight Concern, Eating Concern, Shape Concern, and Restraint, with five items registering value loading of $<0.30$. Thus, the present study aims to further extend the Malay EDE-Q 6.0 research contribution by broadening the population and age group.

The primary goal of this study is to adapt the original English EDE-Q 6.0 into the Malay language, offering a semantically and contextually relevant tool for Malaysian use. A supplementary aim was to adapt EAT26 to accomplish the Malay EDE-Q 6.0 convergent validity evaluation. Second, the study aims to appraise the factorial structure and examine associations between the Malay EDE-Q 6.0 and another measure of eating disorder symptoms (Malay EAT-26) and association with the quality of life (QoL) construct among a sample of university students in Malaysia. Therefore, it is hypothesized that Malay EDE-Q 6.0's factor structure will be similar to the four-factor structure discovered by Ramli et al. (2008) on the earlier Malay EDE-Q version.

\section{Method}

\subsection{Participants}

University students from various disciplines in a public university in Klang Valley, Malaysia, were approached to participate in this study. Six hundred questionnaires were distributed, of which, 595 were returned (99.2\% response rate). Around 43\% participants were male $(n=255)$ and $57 \%$ were female $(n=340)$. All participants were bilingual Malaysians (Malay - native language; English - instructional medium of the university). The rationale for recruiting university students was that the median age for the onset of ED is typically between 18 and 21 years (Hudson et al., 2007), which corresponds to the average age of university students. Following an interval of two weeks, a total of 234 participants (121 males and 113 females; 39.3\% return rate) who agreed to participate in the test-retest reliability study were enlisted.

\subsection{Measures}

A paper-based questionnaire comprising of two sections: 1) sociodemographic and 2) all related inventories, with 20 min completion time, were distributed to the participants. Aside from the common sociodemographic items, the participants' self-reported weight and height were also included. The second section had the EDE-Q 6.0 and EAT-26 Malay versions of the questionnaire (convergent validity procedure). The scale representing the QoL was likewise incorporated (divergent validity procedure). For divergence evidence, the QoL construct was selected for its assumed theoretical difference. Its selection was also made based on the review in the literature that displays paucity of QoL construct assessed against ED (Padierna et al., 2000). We used the Malay and English versions of the EDE-Q to assess the equivalent form's reliability.

\subsubsection{Malay Eating Disorder Examination-Questionnaire 6.0 (EDE-Q 6.0)}

The EDE-Q 6.0 (Fairburn \& Beglin, 2008) is a 28 items self-report questionnaire of ED-associated symptoms with a 7-point scale of 0-6, and a severity screener of the last 28 days. Items 13 to 18 - on behavioral frequency rather than severity - were excluded from the data analysis. Twenty-two items in the EDE-Q 6.0 constitute four subscales: weight concern, shape concern, eating concern, and restraint. The scores for relevant items under each subscale are added together and divided by the number of items to obtain the subscale scores. The mean total subscale scores signify the global score.

\subsubsection{Malay Eating Attitude Test-26 (EAT-26)}

The EAT-26 (Garner et al., 1982) is a 26 items screener of ED attitudes and behavior severity, scaled on a 6-point scale of 1 "never" to 6 "always". A high EAT-26 total score indicates a greater level of EDrelated attitude and behavior, whereas a total score exceeding 20 warrants further investigation by qualified health professionals. The EAT-26 three main areas are oral control, bulimia and food preoccupation, and dieting. Malay adapted EAT-26 of the extant study registered a good overall internal reliability $(\alpha=0.81)$.

\subsubsection{Malay World Health Organization Quality of Life Brief (WHO-QoL- BREF-Malay)}

The Malay WHO-QoL-BREF consisted of 26 items with a 5-point scale to measure the QoL within four areas: environmental, social, psychological, and physical health. A rating from 1 to 5 is given for every item in which a higher score represents greater satisfaction. The internal consistency of the Malay WHO-QoL-BREF version ranged between $\alpha=$ 0.64 and 0.80 in the four areas with test-retest reliability from 0.49 to 0.88 (Hasanah et al., 2003). These results were compared with the internal reliability found in this study: $\alpha=0.60,0.76,0.78$, and 0.79 for social, physical, psychological, and environmental health, respectively. However, the social health domain that generated the lowest internal reliability should be read with caution; since it was based on three items (Item 20, 21, and 22) (Hasanah et al., 2003). Nonetheless, this study found that the overall items produced excellent internal reliability $(\alpha=$ 0.91).

\subsection{Procedure}

\subsubsection{Adaptation procedure}

The adaptation procedure was based on the guidelines for "Test Adaptation' issued by the International Test Commission (International Test Commission, 2017). Initially, the English EDE-Q 6.0 was translated into Malay by a certified translator and another independent bilingual translator who back-translated it into English. Then, forward and backward translations were harmonized using another independent bilingual expert - who held a clinical psychology doctoral qualification to ensure all items were semantically, contextually, and conceptually relevant.

\subsubsection{Pretesting and pilot procedure}

Before the full-scale study, pretesting and pilot studies were conducted on psychology undergraduate students $(N=115$; Mohd Taib \& Abdul Khaiyom, 2020) to ensure the future success of the study. In addition, pretesting and pilot studies were carried out to solicit feedback on the time length of completing the questionnaire and evidence of item clarity and instruction intelligibility (Mohd Taib \& Abdul Khaiyom, 2020).

\subsubsection{Main study procedure}

The main study used a cross-sectional survey-based research design. Stratified random sampling was carried out to ensure the representativeness of all faculties in the university, as suggested by Hasim and Abdul Khaiyom (2019) and Breakwell et al. (2012). The participants were recruited in numerous recruitment sessions held in each affiliated faculties. The students who agreed to participate were initially briefed before completing a consent form and they immediately received a pack of surveys to complete. At first, the participants completed the Malay package of EDE-Q 6.0 and other inventories before completing the original English EDE-Q 6.0. Upon survey submission, participants were invited to participate in a re-test session, which was to be held within two weeks. Interested participants were personally contacted and approached by the researchers.

\subsubsection{Ethical procedure}

Before the data collection process began, approval was sought from 
the Institutional Research Ethics Committee (ID No: IREC 2018-228). All those participating in the study were informed regarding the research and their rights. They were then issued an information sheet and a written informed consent sheet that had to be signed before completing the questionnaires.

\subsubsection{Statistical analyses}

Before analyzing the data, it was first cleaned, and the notions surrounding the testing were fulfilled. The missing data for each variable ranged from $0.2 \%$ to $2 \%$, and any missing data were imputed by a single imputation technique, which is an appropriate procedure for missing data below 5\% (Tabachnick et al., 2007). The structure of the factors in the adapted Malay EDE-Q 6.0 was examined through EFA with direct oblimin rotation and principal axis factor extraction. Three criteria for factor extraction included: scree plot identification, Eigenvalue $>1$ criterion (Kaiser, 1960), and higher item loading greater than 0.30 (Tabachnick et al., 2007). Cronbach's alpha assessed internal reliability. For test-retest reliability, convergent and divergent validities, Pearson's correlations were used. The items between the two versions (Malay and the original English version) were correlated with Pearson's correlations for equivalent reliability. Cohen (1988) interprets the strength of correlations value as weak when $r=0.10$ to 0.29 , moderate when $r=0.30$ to 0.49 , and strong when $r=0.50$ to 1.00 . All data were analyzed using IBM SPSS 25.0 (IBM Corp., 2017).

\section{Results}

\subsection{Sociodemographic}

The mean age of participants was 21.9 years $(S D=1.20$; range $=$ 19-28). Most participants were Malay (98.3\%), and the remaining participants were of other races. The average body mass index (BMI) was $23.2(S D=4.9$; range $=14.4-47.7)$. Nine $(1.5 \%)$ participants were married, whereas others were unmarried $(98.5 \%)$. About half of the respondents were undergraduates $(47.7 \%)$, and the rest were postgraduates. Notably, there was no significant age difference between the initial and the re-enlisted group of participants. However, the re-enlisted group recorded a significantly higher average BMI of $23.8(S D=5.5$; range $=15.8-47.7$, with a higher proportion of males $(51.7 \%)$ when compared with females (48.3\%). On examining each item in the EDE-Q 6.0 Malay version, only items $3,6,9,10$, and 22 exhibited a significant difference in the scores between males and females.

\subsection{Factor structure}

The EFA produced four factors (restraint, shape and weight concerns, eating concerns, and shape/weight overvaluation) with a cumulative variance of $63.8 \%$, supported by a scree plot analysis and higher items loading greater than 0.30 . Thus, all items were retained. However, the content of the resultant four factors did not align with its original four factors (see Table 1 for factor and item loadings).

The first factor, restraint, accounted for $43 \%$ of the total accumulated variance, encompassing the first five items of the original subscale (Fairburn \& Beglin, 2008). The content of the resultant second factor consists of six retained items from the original shape and weight concerns, three items of weight concern, and an item from eating concern (Fairburn \& Beglin, 2008). Factor three, the eating concern, preserved all its original items except item 20 (now in factor 2), which was replaced by item 8 (initially from factors 3 and 4). Finally, the shape/ weight overvaluation factor accounted for $5 \%$ of the total variance with two items; 22 and 23. Notably, the shape/weight overvaluation factor was also revealed in the previous study of the earlier EDE-Q English version (32 item EDE-Q; Grilo et al., 2015).

\subsection{Reliabilities of the Malay EDE-Q 6.0}

The global score of the Malay EDE-6.0 version of the questionnaire registered excellent internal reliability $(\alpha=0.93)$, and the test-retest reliability indicated a strong correlation $(r=0.83, p<0.01$ ), suggesting solid temporal stability between the first and the second administration point.

Equivalence reliability of items in both the original English and

Table 1

Pattern matrix of the principal axis factoring of the 22 items of the EDE-Q 6.0 Malay questionnaire $(N=595)$.

\begin{tabular}{|c|c|c|c|c|c|}
\hline & Item & $\begin{array}{l}\text { Factor } 1 \\
\text { Restraint }\end{array}$ & $\begin{array}{l}\text { Factor } 2 \text { Shape and weight } \\
\text { concerns }\end{array}$ & $\begin{array}{l}\text { Factor } 3 \text { Eating } \\
\text { concern }\end{array}$ & $\begin{array}{l}\text { Factor } 4 \text { Shape/weight } \\
\text { overvaluation }\end{array}$ \\
\hline 1 & Restraint overeating & 0.83 & 0.11 & -0.16 & -0.05 \\
\hline 3 & Food avoidance & 0.69 & -0.06 & 0.02 & 0.10 \\
\hline 4 & Dietary rules & 0.69 & -0.03 & 0.02 & 0.01 \\
\hline 2 & Avoidance of eating & 0.56 & -0.05 & 0.07 & 0.06 \\
\hline 5 & Empty stomach & 0.47 & 0.10 & 0.16 & 0.02 \\
\hline 25 & Dissatisfaction with weight & -0.08 & 0.85 & -0.01 & 0.18 \\
\hline 26 & Dissatisfaction with shape & -0.07 & 0.84 & -0.02 & 0.22 \\
\hline 27 & Discomfort seeing body & -0.04 & 0.83 & 0.03 & 0.15 \\
\hline 28 & Avoidance of exposure & -0.09 & 0.79 & 0.00 & 0.15 \\
\hline 11 & Feelings of fatness & 0.14 & 0.77 & -0.00 & -0.18 \\
\hline 12 & Desire to lose weight & 0.26 & 0.70 & 0.01 & -0.24 \\
\hline 24 & Reaction to prescribed weighing & 0.04 & 0.57 & 0.10 & 0.19 \\
\hline 10 & Fear of weight gain & 0.15 & 0.55 & 0.27 & -0.21 \\
\hline 6 & Flat stomach & 0.25 & 0.38 & 0.08 & -0.14 \\
\hline 20 & Guilt about eating & 0.26 & 0.32 & 0.29 & 0.09 \\
\hline 7 & $\begin{array}{l}\text { Preoccupation with food, eating or } \\
\text { calories }\end{array}$ & -0.02 & -0.11 & 0.80 & 0.00 \\
\hline 8 & Preoccupation with shape or weight & -0.09 & 0.09 & 0.79 & 0.00 \\
\hline 9 & Fear of losing control over eating & 0.13 & 0.32 & 0.38 & -0.05 \\
\hline 19 & Eating in secret & 0.12 & 0.01 & 0.34 & 0.06 \\
\hline 21 & Social eating & & & 0.30 & \\
\hline 22 & Importance of weight & 0.19 & 0.23 & 0.11 & 0.65 \\
\hline 23 & Importance of shape & 0.17 & 0.22 & 0.10 & 0.65 \\
\hline $\begin{array}{l}\text { Internal } \\
\quad \text { reliability }\end{array}$ & & 0.80 & 0.92 & 0.75 & 0.91 \\
\hline Eigenvalue & & 9.46 & 1.98 & 1.49 & 1.11 \\
\hline$\%$ variance & & 42.99 & 9.00 & 6.75 & 5.04 \\
\hline
\end{tabular}

The bold values indicate the items loaded in which factors. 
Malay EDE-Q 6.0 displayed a range of correlations coefficients of $r=$ 0.63 to $0.86(p<0.01)$ with item 7 (thinking about food, eating, or calories, made it difficult to concentrate on things one is interested in (for example, working, following a conversation or reading) and its translated item (Anda telah memikirkan tentang makanan, makan atau kalori, sehingga menjadikan anda sukar untuk menumpukan perhatian pada perkara yang anda sukai (contohnya bekerja, mengikuti perbualan atau membaca) registering the lowest correlation and item 12 recorded the highest correlation (Have you had a desire to lose weight?/Anda mempunyai keinginan yang kuat untuk menurunkan berat badan?). Hence, the Malay EDE-Q 6.0 items registered strong and positive correlations with the items of its original version. Therefore, both scales (the original and adapted versions) could be confidently administered to the Malaysian population, taking into account the high scale equivalency.

\subsection{Validities of Malay EDE-Q 6.0}

The correlation between Malay EDE-Q 6.0 and EAT-26 served as the convergent validity evidence. The result suggested a strong correlation between the two measures with $r=0.53$ at a 0.01 significance level. In the effort of establishing divergent evidence of the Malay EDE-Q 6.0, a measurement gauging a theoretically dissimilar construct of QoL was used. Though the resultant correlation notably registered $r=0.27$, indicating low magnitude, it is still not nearly zero to concur with the acceptable degree of divergent evidence. Descriptive statistics, correlations, and gender differences at the two test-retest times among the global and subscale scores of the Malay EDE-Q 6.0 and its criterion measures are depicted in Tables 2 and 3.

\section{Discussion}

The extant study adapted the original English EDE-Q 6.0 into the Malay language and evaluated its psychometric properties among Malaysian university students. The EFA factors derived in this research, however, differed from its original four theoretical subscales. For example, all items of factor 1 (restraint) were retained - similar to its original factor 1 . In contrast, factor 2 (shape and weight concerns) items were a combination of the original subscales of shape and weight concern. Similarly, a study by Peterson et al. (2007) and a review conducted by Rand-Giovannetti et al. (2017) suggested a combination of weight and shape concern subscales into one factor earlier and the present version of EDE-Q. Nevertheless, Peterson et al. (2007) found three factors instead of four, among Britons. For factor 3 (eating concern), item 20 was excluded and item 8 was added. This item was previously a double-barrel item loaded under two original subscales of weight concern and shape concern (Fairburn \& Beglin, 2008).

According to Hudson et al. (2007), approximately 25\% of ED cases are among males in the general American population. Nonetheless, the present study exhibits no significant difference between males and females in the global scores of the Malay EDE-Q 6.0, and only five out of 22 items had significant gender score differences. Females indicated the highest score on item 11 - the feeling of being fat, whereas males stated the same on item 26 - dissatisfaction with shape. A similar concern was depicted in a study on body shape dissatisfaction, body shape concern, and body image perception among Malaysian undergraduate students. The study results indicate different gender-based concerns of body image perception, with males registering concern on muscular fitness, and females on thinness (Kamaria et al., 2016).

The overall results indicated good internal, equivalent, and testretest reliabilities of the Malay EDE-Q 6.0. Furthermore, its internal reliability value stands at similar acceptable global and subscales levels values, as registered in the EDE-Q 6.0 adapted studies in Japanese (Mitsui et al., 2017), Norwegian (Friborg et al., 2013; Reas, et al., 2012; Rø et al., 2015), Portuguese (Machado et al., 2014), Italian (Calugi et al., 2017), French (Carrard et al., 2015), and German (Hilbert et al., 2012) populations.

The adapted EDE-Q 6.0 version of the questionnaire registered high temporal stability when tested for more than 14 days. The result is consistent with two studies yielding an acceptable EDE-Q 6.0 test-retest correlation when tested for seven to ten days (Calugi et al., 2017; Rose et al., 2013). In addition, the original English and Malay EDE-Q 6.0 registered significantly strong and positive items/test correlation(s), suggesting language equivalence. However, the Malay EDE-Q global score was also compared with the score obtained from a nonclinical sample of other cultures with a similar age group (Rose et al., 2013; Calugi et al., 2017; Mitsui et al., 2017). The result suggests that the interpretation of items of various adaptations of measure is similar regardless of cross-cultural differences.

Moreover, the Malay EDE-Q 6.0 generated acceptable convergent validities. The present results suggest that Malay EDE-Q 6.0 and Malay EAT-26 are measuring a construct similar to the ED. A similar report of moderate correlations of EDE-Q 6.0 and EAT-26 subscales were suggested by Mitsui et al. (2017). Moreover, the divergent validity was limitedly supported by a significantly low correlation of the Malay EDEQ 6.0 and Malay WHO-QoL-BREF. The negative correlations between the scales provide evidence that ED symptoms may be associated with the impairment in the QoL of an individual regarding either their physical, psychological, or social health. The finding is similar to a review by Jenkins et al. (2011), suggesting a significant impact on the psychological aspect of QoL in individuals with EDs.

The present study has made several contributions to theoretical and research development. It is the first to examine the Malay EDE-Q 6.0 psychometric properties on a Malay population. Second, this study applies a rigorous method in testing its adaptation, as suggested by the

Table 2

Correlations between global and subscale score of the Malay EDE-Q 6.0 and its criterion measures.

\begin{tabular}{|c|c|c|c|c|c|c|c|c|c|}
\hline \multirow[t]{2}{*}{ Measures } & \multirow[b]{2}{*}{1.1} & \multirow[b]{2}{*}{1.2} & \multirow[b]{2}{*}{1.3} & \multirow[b]{2}{*}{1.4} & \multirow[b]{2}{*}{2} & \multirow[b]{2}{*}{2.1} & \multirow[b]{2}{*}{2.2} & \multirow[b]{2}{*}{2.3} & \multirow[b]{2}{*}{3} \\
\hline & & & & & & & & & \\
\hline 1. Global Score of Adapted Malay EDE-Q 6.0 & $0.73^{* *}$ & $0.89^{* *}$ & $0.80^{* *}$ & $0.81^{* *}$ & $0.53^{* *}$ & $0.63^{* *}$ & $0.33^{* * *}$ & 0.08 & $-0.27^{* *}$ \\
\hline 1.1 Factor 1 Restraint & & $0.57^{* *}$ & $0.50^{* *}$ & $0.37^{* *}$ & $0.43^{* *}$ & $0.53^{* *}$ & $0.18^{* *}$ & $0.10^{*}$ & $-0.11^{* *}$ \\
\hline 1.2 Factor 2 Shape and Weight Concerns & & & $0.64^{* *}$ & $0.60^{* *}$ & $0.46^{* *}$ & $0.58^{* *}$ & $0.28^{* * *}$ & 0.01 & $-0.26^{* *}$ \\
\hline 1.3 Factor 3 Eating Concerns & & & & $0.53^{\text {*** }}$ & $0.50^{* *}$ & $0.51^{* *}$ & $0.39^{* * *}$ & $0.17^{* *}$ & $-0.28^{* *}$ \\
\hline 1.4 Factor 4 Shape/Weight Overvaluation & & & & & $0.37^{* *}$ & $0.42^{* *}$ & $0.27^{* *}$ & 0.06 & $-0.23^{* *}$ \\
\hline 2. Adapted Malay EAT-26 & & & & & & $0.87^{* *}$ & $0.73^{* *}$ & $0.64^{* *}$ & $-0.16^{* *}$ \\
\hline 2.1 Dieting Subscale & & & & & & & $0.47^{* *}$ & $0.26^{* *}$ & $-0.14^{* *}$ \\
\hline 2.2 Bulimia and Food Preoccupation Subscale & & & & & & & & $0.41^{* *}$ & $-0.15^{* *}$ \\
\hline 2.3 Oral Control & & & & & & & & & -0.06 \\
\hline 3. WHO-QoL-BREF-Malay & & & & & & & & & \\
\hline
\end{tabular}

Notes. Measures: EDE-Q 6.0 = Eating Disorder Examination Questionnaire 6.0 (EDE-Q 6.0), EAT-26 = Eating Attitude Test-26, WHO-QoL-BREF-Malay = World Health Organization Quality of Life Brief Version Malay.

** Correlation is significant at 0.01 (two-tailed).

"Correlation is significant at 0.05 (two-tailed). 
Table 3

Means (standard deviation) for Malay EDE-Q 6.0 and its criterion measures at Time $1(\mathrm{~N}=595)$ and Time $2(n=234)$.

\begin{tabular}{|c|c|c|c|c|c|c|}
\hline \multirow[t]{2}{*}{ Measures } & \multicolumn{6}{|l|}{ Mean } \\
\hline & $\begin{array}{l}\text { Mean at Time } 1 \\
\text { (SD) }\end{array}$ & $\begin{array}{l}\text { Mean at Time } 2 \\
\text { (SD) }\end{array}$ & $\begin{array}{l}\text { Males Mean Time } 1 \\
\text { (SD) }\end{array}$ & $\begin{array}{l}\text { Females Mean Time } 1 \\
\text { (SD) }\end{array}$ & $\begin{array}{l}\text { Males Mean Time } 2 \\
\text { (SD) }\end{array}$ & $\begin{array}{l}\text { Females Mean Time } 2 \\
\text { (SD) }\end{array}$ \\
\hline $\begin{array}{l}\text { 1. Global Score of Adapted Malay } \\
\text { EDE-Q } 6.0\end{array}$ & $1.49(1.13)$ & $1.35(1.16)$ & $1.40(1.17)$ & $1.55(1.10)$ & $1.23(1.18)$ & $1.46(1.13)$ \\
\hline 1.1 Factor 1 Restraint & $1.04(1.22)$ & $0.98(1.21)$ & $1.07(1.28)$ & $1.02(1.17)$ & $0.97(1.13)$ & $0.98(1.08)$ \\
\hline $\begin{array}{l}\text { 1.2 Factor } 2 \text { Shape and Weight } \\
\text { Concerns }\end{array}$ & $2.28(1.65)$ & $1.96(1.63)$ & $2.00(1.62)$ & $2.49(1.64)^{* *}$ & $1.71(1.54)$ & $2.21(1.69)^{*}$ \\
\hline 1.3 Factor 3 Eating Concerns & $0.85(1.06)$ & $0.81(1.05)$ & $0.79(1.07)$ & $0.89(1.05)$ & $0.74(1.07)$ & $0.88(1.04)$ \\
\hline $\begin{array}{l}\text { 1.4 Factor } 4 \text { Shape/Weight } \\
\text { Overvaluation }\end{array}$ & $1.77(1.64)$ & $1.65(1.64)$ & $1.74(1.70)$ & $1.80(1.61)$ & $1.52(1.63)$ & $1.78(1.66)$ \\
\hline 2. Adapted Malay EAT-26 & $9.68(8.34)$ & $8.22(10.17)$ & $8.84(7.33)$ & $10.31(8.98)^{*}$ & 7.88 (11.29) & $8.60(8.85)$ \\
\hline 3. WHO-QoL-BREF-Malay & $92.81(12.57)$ & $89.68(12.91)$ & $93.25(11.41)$ & $92.49(11.92)$ & $89.84(13.76)$ & $89.50(12.00)$ \\
\hline
\end{tabular}

Notes. Measures: EDE-Q 6.0 = Eating Disorder Examination Questionnaire 6.0 (EDE-Q 6.0), EAT-26 = Eating Attitude Test-26, WHO-QoL-BREF-Malay = World Health Organization Quality of Life Brief Version Malay.

Significant difference at $p \leq 0.01$ (two-tailed).

* Significant difference at $p \leq 0.05$ (two-tailed).

international guidelines (International Test Commission, 2017). Third, the study was conducted on a relatively large sample representing both male and female students from different faculties in a university, which allowed EFA to yield information on the underlying constructs of EDs.

However, several limitations are inherent in this study. First, the sample comprises only university students; thus, future studies should recruit samples from different settings, such as the general community and clinical settings, to increase the generalizability of the results. Second, self-reporting might have underestimated or overestimated the ED psychopathology because of its possible retrospective or recall bias. Third, the present study only explored the factor structure of the Malay version of EDE-Q 6.0 by using EFA. Therefore, future studies should consider confirmatory factor analysis to confirm the present factor model.

\section{Conclusion}

Screening for eating disorders is important in its early detection, leading to early intervention and a better outcome. A validated screener is necessary to assist clinicians in the assessment. This study provided a comprehensive validation and evaluation of the ED factor structure based on the most recent and widely accepted ED measures. The results suggest that the adapted Malay EDE-Q 6.0 is a valid and reliable tool for assessing ED psychopathology among university students in Malaysia. Accordingly, future assessments can use this tool to assist in developing research in EDs and aid in the production of ED epidemiological data in Malaysia.

\section{Authorship statement}

Conception and design of study: N. Mohd Taib, - - J. H. Abdul Khaiyom;

acquisition of data: N. Mohd Taib, J. H. Abdul Khaiyom;

analysis and/or interpretation of data: N. Mohd Taib, J. H. Abdul

Khaiyom.

Drafting the manuscript: N. Mohd Taib, J. H. Abdul Khaiyom;

revising the manuscript critically for important intellectual content: J. Fauzaman, J. H. Abdul Khaiyom;

Approval of the version of the manuscript to be published (the names of all authors must be listed): N. Mohd Taib, J. Fauzaman, J. H. Abdul Khaiyom.

\section{Declaration of competing interest}

The authors declare that they have no known competing financial interests or personal relationships that could have appeared to influence the work reported in this paper.

\section{References}

Barnes, J., Prescott, T., \& Muncer, S. (2012). Confirmatory factor analysis for the Eating Disorder Examination Questionnaire: Evidence supporting a three-factor model. Eating Behaviors, 13(4), 379-381. https://doi.org/10.1016/j.eatbeh.2012.05.001.

Breakwell, G. M., Wright, D. B., \& Smith, J. A. (2012). Research questions and planning research. In Research methods in psychology (4th ed., pp. 3-15). Sage Publications.

Buhrich, N. (1981). Frequency of presentation of anorexia nervosa in Malaysia. Australian and New Zealand Journal of Psychiatry, 15(2), 153-155.

Calugi, S., Milanese, C., Sartirana, M., El Ghoch, M., Sartori, F., Geccherle, E., ... Dalle Grave, R. (2017). The Eating Disorder Examination Questionnaire: Reliability and validity of the Italian version. Eating and Weight Disorders-Studies on Anorexia, Bulimia and Obesity, 22(3), 509-514. https://doi.org/10.1007/s40519-016-0276-6.

Carrard, I., Rebetez, M. M. L., Mobbs, O., \& Van der Linden, M. (2015). Factor structure of a French version of the eating disorder examination-questionnaire among women with and without binge eating disorder symptoms. Eating and Weight DisordersStudies on Anorexia, Bulimia and Obesity, 20(1), 137-144. https://doi.org/10.1007/ s40519-014-0148-x.

Cohen, J. (1988). Statistical Power Analysis for the Behavioral Sciences (2nd ed.). Erlbaum.

IBM Corp. (2017). IBM SPSS statistics for windows, (version 25.0) [computer software]. Armonk, NY: IBM Corp.

Darcy, A. M., Hardy, K. K., Crosby, R. D., Lock, J., \& Peebles, R. (2013). Factor structure of the Eating Disorder Examination Questionnaire (EDE-Q) in male and female college athletes. Body Image, 10(3), 399-405. https://doi.org/10.1016/j. bodyim.2013.01.008.

Fairburn, C. G., \& Beglin, S. J. (1994). Assessment of eating disorders: Interview or selfreport questionnaire? International Journal of Eating Disorders, 16(4), 363-370. https://doi.org/10.1002/1098-108X(199412)16:4\%3C363::AID-EAT2260160405\% 3E3.0.CO;2- $\% 23$.

Fairburn, C. G., \& Beglin, S. J. (2008). Eating Disorder Examination Questionnaire. Cognitive Behaviour Therapy and Eating Disorders, 309, 313.

Friborg, O., Reas, D. L., Rosenvinge, J. H., \& Rø, Ø. (2013). Core pathology of eating disorders as measured by the Eating Disorder Examination Questionnaire (EDEQ): The predictive role of a nested general $(\mathrm{g})$ and primary factors. International Journal of Methods in Psychiatric Research, 22(3), 195-203. https://doi.org/10.1002/ mpr.1389.

Garner, D. M. (1991). Eating Disorder Inventory-2. Odessa, FL: Psychological Assessment Resources.

Garner, D. M., Olmsted, M. P., Bohr, Y., \& Garfinkel, P. E. (1982). The Eating Attitudes Test: Psychometric features and clinical correlates. Psychological Medicine, 12(4), 871-878. https://doi.org/10.1017/S0033291700049163.

Grilo, C. M., Reas, D. L., Hopwood, C. J., \& Crosby, R. D. (2015). Factor structure and construct validity of the eating disorder examination-questionnaire in college students: Further support for a modified brief version. International Journal of Eating Disorders, 48(3), 284-289. https://doi.org/10.1007/s11695-012-0840-8.

Hasanah, C. I., Naing, L., \& Rahman, A. R. A. (2003). World Health Organization quality of life assessment: Brief version in Bahasa Malaysia. Medical Journal of Malaysia, 58 (1), 79-88.

Hasim, S. I., \& Abdul Khaiyom, J. H. (2019). Adaptation and validation of the Malay version of daily record of severity of problems (DRSP) among undergraduate students in a university in Malaysia. Malaysian Journal of Psychiatry, 28(1). https://www.mjpsychiatry.org/index.php/mjp/article/view/491.

Hilbert, A., De Zwaan, M., \& Braehler, E. (2012). How frequent are eating disturbances in the population? Norms of the Eating Disorder Examination-Questionnaire. PLoS One, 7(1), 1-5. https://doi.org/10.1371/journal.pone.0029125.

Hudson, J. I., Hiripi, E., Pope, H. G., Jr., \& Kessler, R. C. (2007). The prevalence and correlates of eating disorders in the National Comorbidity Survey Replication. 
Biological Psychiatry, 61(3), 348-358. https://doi.org/10.1016/j. biopsych.2006.03.040.

International Test Commission. (2017). The ITC Guidelines for Translating and Adapting Tests (2nd ed.). International Test Commission https://www.intestcom.org/files/ guideline test adaptation 2ed.pdf.

Jenkins, P. E., Hoste, R. R., Meyer, C., \& Blissett, J. M. (2011). Eating disorders and quality of life: A review of the literature. Clinical Psychology Review, 31(1), 113-121. https://doi.org/10.1016/j.cpr.2010.08.003.

Kaiser, H. F. (1960). The application of electronic computers to factor analysis. Educational and Psychological Measurement, 20(1), 141-151 (doi:10.1177\% 2F001316446002000116).

Kamaria, K., Vikram, M., \& Ayiesah, R. (2016). Body image perception, body shape concern and body shape dissatisfaction among undergraduates students. Jurnal Teknologi, 78(6), 37-42. https://doi.org/10.11113/jt.v78.9050.

Machado, P. P., Martins, C., Vaz, A. R., Conceição, E., Bastos, A. P., \& Gonçalves, S. (2014). Eating disorder examination questionnaire: Psychometric properties and norms for the Portuguese population. European Eating Disorders Review, 22(6), 448-453. https://doi.org/10.1002/erv.2318.

Mitsui, T., Yoshida, T., \& Komaki, G. (2017). Psychometric properties of the eating disorder examination-questionnaire in Japanese adolescents. BioPsychoSocial Medicine, 11(1), 1-9 (https://dx.doi.org/10.1186\%2Fs13030-017-0094-8).

Mohd Taib, N., \& Abdul Khaiyom, J. H. (2019). Validation of the Malay version of Eating Disorder Examination-Questionnaire 6.0 (EDE-Q 6.0) among undergraduate students: A study protocol. Malaysian Journal of Psychiatry, 28(1). https://www. mjpsychiatry.org/index.php/mjp/article/view/494.

Mohd Taib, N., \& Abdul Khaiyom, J. H. (2020). Adaptation and validation of the Malay Eating Disorder Examination-Questionnaire 6.0 (EDE-Q 6.0) among university students: A pilot study. Malaysian Journal of Psychiatry, 30(1).

Padierna, A., Quintana, J. M., Arostegui, I., Gonzalez, N., \& Horcajo, M. J. (2000). The health-related quality of life in eating disorders. Quality of Life Research, 9(6), 667-674.

Parker, K., Mitchell, S., O'Brien, P., \& Brennan, L. (2015). Psychometric evaluation of disordered eating measures in bariatric surgery patients. Eating Behaviors, 19, 39-48. https://doi.org/10.1016/j.eatbeh.2015.05.007.
Peterson, C. B., Crosby, R. D., Wonderlich, S. A., Joiner, T., Crow, S. J., Mitchell, J. E., ,.. le Grange, D. (2007). Psychometric properties of the eating disorder examinationquestionnaire: Factor structure and internal consistency. International Journal of Eating Disorders, 40(4), 386-389. https://doi.org/10.1002/eat.20373.

Pike, K. M., \& Dunne, P. E. (2015). The rise of eating disorders in Asia: A review. Journal of Eating Disorders, 3(1), 33.

Ramli, M., Jamaiyah, H., Azimah, N., Khairani, O., \& Adam, B. (2008). Cross-cultural adaptation and validation of the Bahasa Malaysia version of the Eating Disorder Examination Questionnaire (EDE-Q). Malaysian Journal of Psychiatry, 17(2). https: //www.mjpsychiatry.org/index.php/mjp/article/viewFile/41/40.

Rand-Giovannetti, D., Cicero, D. C., Mond, J. M., \& Latner, J. D. (2017). Psychometric properties of the Eating Disorder Examination-Questionnaire (EDE-Q): A confirmatory factor analysis and assessment of measurement invariance by sex. Assessment, 227(1), 164-177, 1073191117738046. (doi:10.1177\% 2F1073191117738046).

Reas, D. L., Øverås, M., \& Rø, Ø. (2012). Norms for the Eating Disorder Examination Questionnaire (EDE-Q) among high school and university men. Eating Disorders, 20 (5), 437-443. https://doi.org/10.1080/10640266.2012.715523.

Rø, Ø., Reas, D. L., \& Stedal, K. (2015). Eating disorder examination questionnaire (EDEQ) in Norwegian adults: Discrimination between female controls and eating disorder patients. European Eating Disorders Review, 23(5), 408-412. https://doi.org/ 10.1002/erv.2372.

Rose, J. S., Vaewsorn, A., Rosselli-Navarra, F., Wilson, G. T., \& Weissman, R. S. (2013). Test-retest reliability of the Eating Disorder Examination-Questionnaire (EDE-Q) in a college sample. Journal of Eating Disorders, 1(42), 1-10 (https://dx.doi.org/ 10.1186\%2F2050-2974-1-42).

Tabachnick, B. G., Fidell, L. S., \& Ullman, J. B. (2007). Using multivariate statistics (Vol. 5). Boston, MA: Pearson.

White, H. J., Haycraft, E., Goodwin, H., \& Meyer, C. (2014). Eating Disorder Examination Questionnaire: Factor structure for adolescent girls and boys. International Journal of Eating Disorders, 47(1), 99-104. https://doi.org/10.1002/eat.22199. 